\title{
EPISTEMIC STANCE NEGOTIATION: SOME EXAMPLES FROM ITALIAN CONVERSATIONS
}

Keywords: epistemic stance, KUB model, alignment, misalignment, sequential structure

\begin{abstract}
According to the results of our previous studies on written texts and spoken dialogues (Zuczkowski et al. 2014; Zuczkowski et al. 2017) it is possible to identify three main epistemic positions, each having two sides, one evidential (source of information), the other epistemic (commitment towards the truth of the propositional content): Knowing/ certain, Not Knowing Whether-Believing/uncertain, Unknowing/neither certain nor uncertain. During a dialogue, speakers can assume one of three different epistemic positions, shifting from one to another in their turns or even within the same turn, and give their interlocutors a complementary one; interlocutors, on their part, can react by showing alignment or misalignment towards the others' positioning. In this study, in order to illustrate our theoretical perspective, we present four conversational excerpts taken from different types of Italian corpora showing the relations between the epistemic positioning and the sequential structure of interactions. Our analysis suggests that, when interlocutors assume epistemic roles consistent with speakers' expectations, the conversational outcomes are agreement and alignment; when this is not the case, disagreement and misalignment are frequent. These dynamics affect the sequential structure of the interaction as well.
\end{abstract}

1 Corresponding author Ramona Bongelli, Department of Political Sciences, Communication and International Relations, University of Macerata, Italy, Via Don Minzoni 22/A, 62100 Macerata, Italy. Tel. +3907332582540. E-mail address: ramona.bongelli@unimc.it 


\section{Introduction}

The study of stance is quite heterogeneous (Englebretson 2007). Normally with this term scholars refer to three different aspects: emotional states ('affective stance'), evaluations ('attitudinal stance'), commitment to the propositional content or degree of reliability ('epistemic stance') (Biber, Finegan 1989; Biber 2004; Jaffe 2009).

In the present paper, we focus our attention exclusively on the epistemic stance or epistemic position, that we use as synonyms. Similarly to Ochs (1996: 410), we consider it as something referring to both the epistemic (commitment) and the evidential (source of information) positions which speakers take during communication.

According to our psychological and linguistic background (Zuczkowski et al. 2017), speakers convey, through lexical and morphosyntactic means, how in the here and now of communication they gain access - perceptively or cognitively ${ }^{2}-$ to a specific propositional content and their commitment to the truth of information (and the degrees of certainty). So, for example, if a speaker says:

\section{(1) Yesterday Matthew was at the skate park}

$\mathrm{s} /$ he conveys (through the declarative structure and the simple past, Zuczkowski et al. 2017) that, in the here and now of communication, s/he gains access to the piece of information through memory and that her/his commitment to the truth of the information is very high (i.e. s/he is certain about it). Obviously, the speaker can dissemble and tell a lie, ${ }^{3}$ but this does not concern the epistemic stance which is a linguistic, communicative concept (not a mental one).

In the field of Conversation Analysis, the main frame of reference on the epistemic stance is John Heritage (2012a, 2012b, 2013), who applies this notion to the analysis of ordinary conversations.

According to him, the "states of knowledge can range from circumstances in which speaker A may have absolute knowledge of some item, while speaker B has none, to those in which both speakers may have exactly equal information, as well as every point in between" (Heritage 2012a: 4).

In his numerous studies on this topic, Heritage pays particularly attention to the informative sequences - these are the sequences in which the interlocutors show different degrees of knowledge concerning some item and drive their talk in order to rebalance the initial epistemic imbalance (Heritage 2012b). "Two main avenues present themselves. First, speakers can position themselves in a relatively unknowing (or K-) position relative to others concerning the matter at hand, thereby initiating sequences by inviting or eliciting information from a projectedly more knowing

2 In the here and now of their experience, human beings can exclusively acquire information through perception - the five senses + proprioception - and through cognition - all that is not perception, such as thought, memory, imagination, etc.

3 While certainty and uncertainty are encoded in communication, truth and falsehood have to do with a subsequent comparison between what a speaker says and the state of affairs s/he refers to. 
(or $\mathrm{K}+$ ) recipient. Alternatively, knowing $(\mathrm{K}+)$ speakers can simply initiate talk concerning the matter at hand, thus launching a sequence, finding a warrant for this conduct by projecting their recipients to be in a relatively unknowing $(\mathrm{K}-)$ position" (Heritage 2012b: 33).

According to Heritage (2010, 2012a), the epistemic imbalance between interlocutors can be of different degrees and it can be represented on an epistemic gradient - which may vary in slope from shallow to deep and that explicitly recalls Akio Kamio's $(1994,1997)$ psychological scales - in which the interlocutors occupy different spatial position.

The dialogical interactions are therefore analyzed on the basis of greater, lesser or equal degree of knowledge which participants display regarding the same piece of information.

\section{Our model of epistemic stance}

According to our model (Bongelli, Zuczkowski 2008; Zuczkowski et al. 2011; Bongelli et al. 2013; Riccioni et al. 2013, 2014; Zuczkowski et al. 2014; Zuczkowski et al. 2017), the issue of the epistemic positions cannot be limited either to knowing or not knowing something or to knowing more, less or equally than the interlocutor.

Our model (1) explicitly adds a third epistemic position to that of knowing and unknowing, that is the not knowing whether/believing; ${ }^{4}$ (2) represents how participants manage their epistemic positions differently from Kamio's and Heritage's, in the sense that it uses neither psychological scales nor epistemic gradients. ${ }^{5}$ We prefer to take into account, at the same time, both the epistemic position from which the speaker conveys his/her message and the epistemic position from which the interlocutor replies, since in this way we are able to evaluate also alignments and misalignments (see Figure 2).

\subsection{Three epistemic positions}

Each of the three above-mentioned epistemic positions has two sides, one evidential (source of information), the other epistemic (commitment toward the truth of the propositional content):

- Knowing/certain position $[\mathrm{K}]$

- Not Knowing Whether-Believing/uncertain position [NKW/B]

- Unknowing/neither certain nor uncertain position [U]

4 The three positions of our model resulted from the analysis of the lexical and grammatical markers of evidentiality and epistemicity in different linguistic corpora, both spoken and written. See, however, Hintikka (1962) for analogous positions in the field of formal epistemic logic.

5 Anyway, psychological scales and gradients are useful to compare participants' degree of knowledge referring to the same piece of information. 
When information is communicated from $\mathrm{K}$ position, it is communicated as known (evidentiality) and certain (epistemicity), as something the speaker says s/he knows to be true. For example, when s/he says Matthew was at the skate-park, s/he communicates that $s$ /he knows the information and that the information is certain for him/her, i.e. his/her commitment towards the truth of it is maximum.

When information is communicated from NKW/B position, it is communicated as possible, probable, supposed, believed, doubtful, suspected, etc., i.e. as uncertain. The NKW/B position is thought of as a continuum that ranges between two poles:

I do not know whether $\mathrm{p}$ or non $\mathrm{p}$

(I am equally uncertain about the two possibilities)
I believe that $\mathrm{p}$

(I am inclined to believe that $\mathrm{p}$ is true)

Figure 1. NKW/B continuum

If a speaker says something like I do not know whether Matthew is at the skate-park (or not), s/he communicates that s/he is equally uncertain about the two possibilities; if s/he says I think that Matthew is at the skate-park, s/he communicates that $\mathrm{s} /$ he is inclined to believe that the information is true.

Finally, from a $\mathrm{U}$ position the information is communicated as neither certain nor uncertain, but simply as missing, as when the speaker says something like I do not know where Matthew is or asks Where is Matthew? In these examples, s/he is communicating that $\mathrm{s}$ /he has no (evidential) access to the piece of information; this informative gap (caused by the absence of the source) becomes, at the same time, a void of (epistemic) commitment (the speaker cannot communicate to be certain or uncertain in relation to information s/he cannot gain access to).

\subsection{Dialogical communication from the epistemic stance perspective}

During a dialogue, speakers can alternatively assume one of the three epistemic positions (shifting from one to another) and simultaneously assign a complementary one to their interlocutors, who can align or misalign with the speakers' expectations. From this perspective, dialogic communication may be seen as originating in one of the three epistemic positions and being directed at another.

For example, the wh-question Where is Matthew? moves from the questioner's U position and is directed to the answerer's $\mathrm{K}$ one $=\mathrm{U} \rightarrow \mathrm{K}$

In principle, the answerer can reply from

- the K position: He is at the skate-park, showing alignment with the questioner's expectation $=\mathrm{K} \rightarrow \mathrm{U}$

- the U position: I do not know where he is, showing misalignment with the questioner's expectation $=\mathrm{U} \rightarrow \mathrm{U}$

- the NKW/B: I think he is at the skate-park, showing partial (mis)alignment with the questioner's expectation $=\mathrm{NKW} / \mathrm{B} \rightarrow \mathrm{U}$ 


\section{alignment}

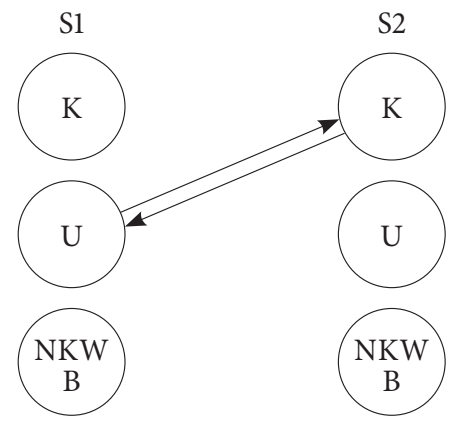

Where is Matthew? He is at the skate-park

misalignment

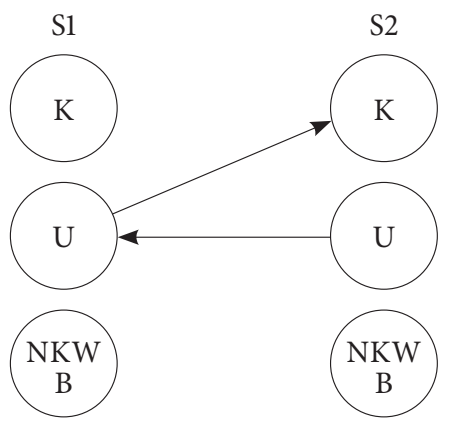

Where is Matthew?
I do not know where he is partial misalignment

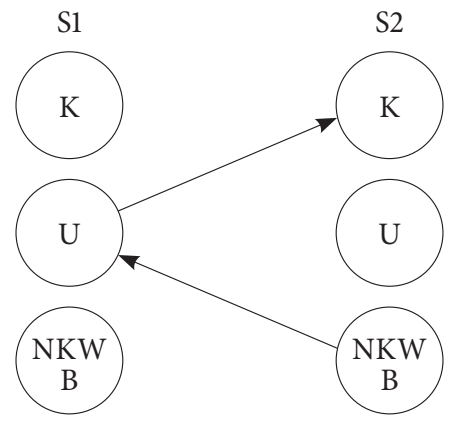

Where is Matthew?

I think he is at the skate-park

Figure 2. Epistemic stances in dialogue

Not all questions are unknowing questions, i.e. not all questions come from the $\mathrm{U}$ position: alternatives and polar questions (polar interrogative, tag and declarative questions) come from NKW/B position (Zuczkowski et al. 2017).

For example, a polar interrogative like Is Matthew at the skate-park? communicates that the questioner does not know whether Matthew is at the skate-park or not, i.e., that s/he is uncertain about which of the two alternatives is true. A tag question like Matthew is at the skate-park, isn't he? communicates that, though the questioner is uncertain about the two possibilities, nonetheless $s /$ he is inclined to think that the lexicalized one is true. The declarative question Matthew is at the skate-park communicates that the questioner is almost completely certain about the propositional content and s/he asks for confirmation. 


\section{Aims}

In the following sections, we apply our model to four excerpts, taken from naturally occurring interactions, in order to show

1. which social actions (Atkinson, Heritage 1984) are performed by the participants; ${ }^{6}$

2. which epistemic positions they assume;

3. whether they align or misalign.

Excerpts (1) and (2) are examples of alignment, while (3) and (4) of misalignment.

The aim of this qualitative analysis is to ascertain whether alignments and misalignments depend on the management not only of the social actions, but also of the epistemic positions and whether these dynamics affect the sequential structure of the interactions.

In order to signal the participants' different epistemic positions and their shifts within the same turn, different colours are used (only for the original Italian transcription): black for the K, blue for the NKW/B and red for the U. We have highlighted not only the single linguistic markers, but also their scope (Quirk et al. 1985). The excerpts are transcribed using the Gail Jefferson transcription system (see Transcription notes at the end of the article).

\section{The analysis of four excerpts}

\subsection{The first excerpt}

The following example is drawn from an informal conversation between two young adult friends, Rachele (R) and Sandro (S), belonging to a corpus of troubles-telling sequences.

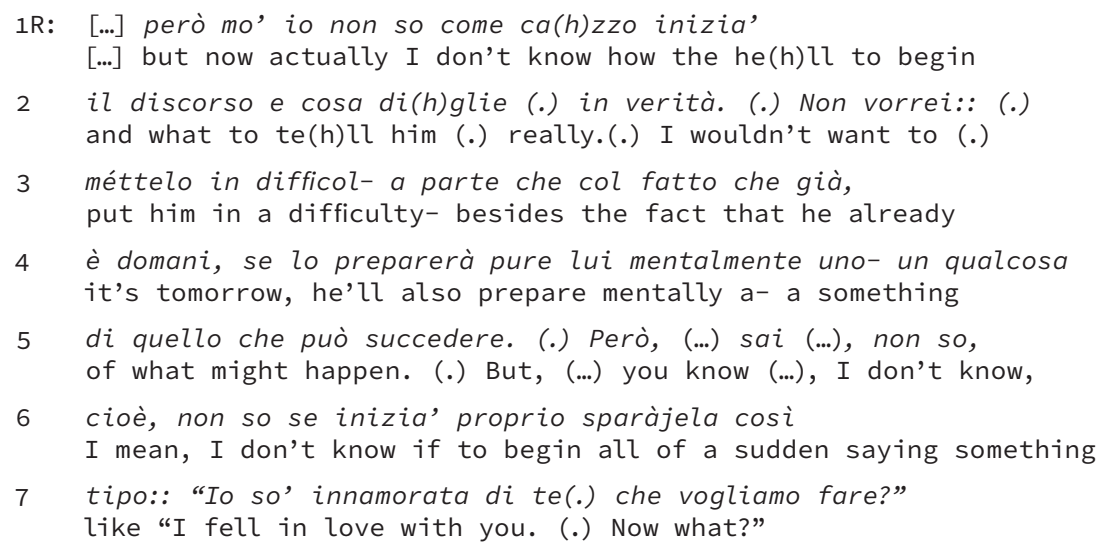

6 The notion of "social action" in Conversation Analysis is close to that of "speech act" in Speech Act Theory. 


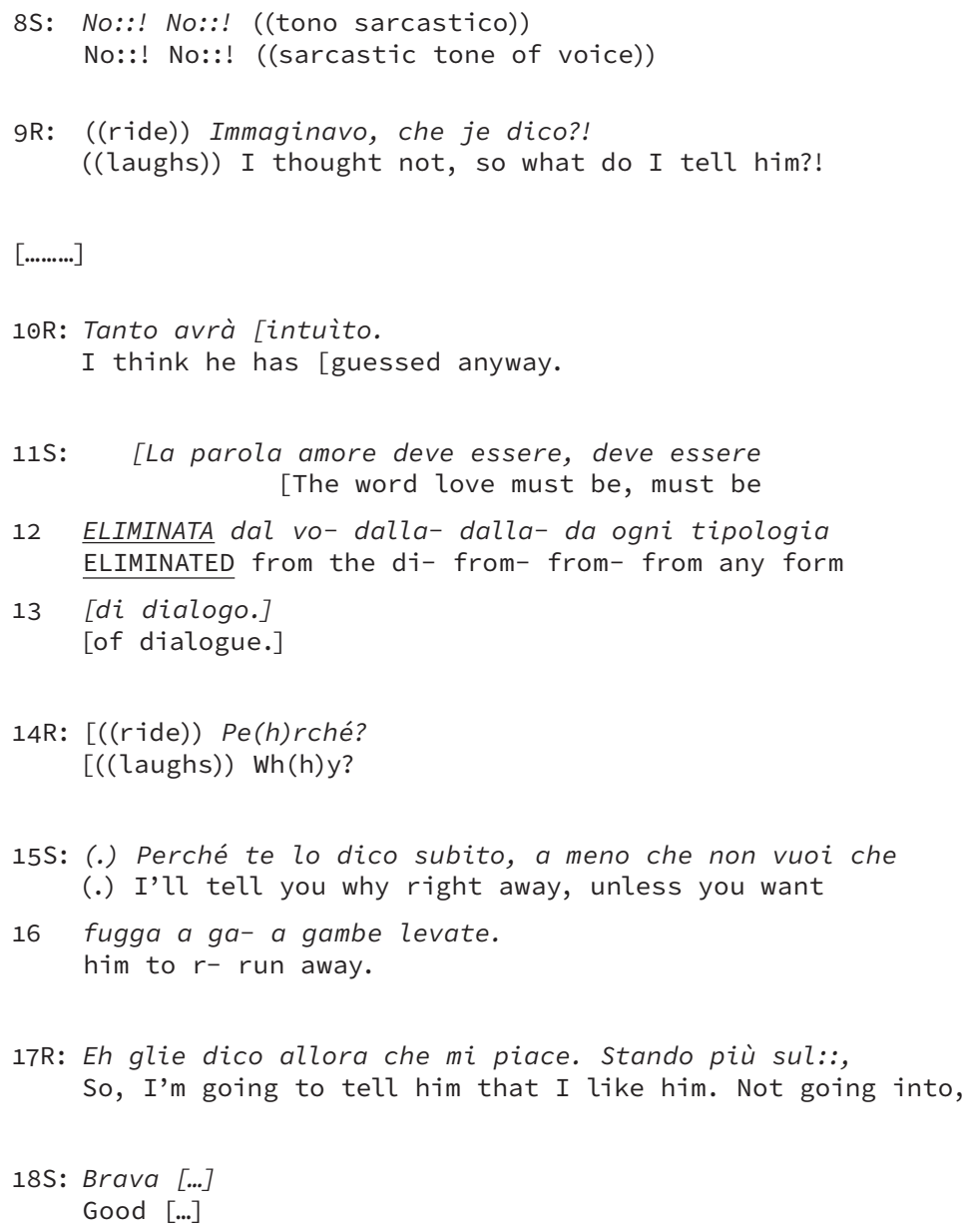

Rachele calls her friend Sandro and explicitly seeks his advice about how to behave with a boy that she likes (and she suspects the feelings are mutual).

The girl shifts from the U position (lines 1-2) to the NKW/B one and considers the possibility of revealing that she is in love with him (lines 5-7), but this possibility is immediately and strongly rejected by Sandro (line 8) from a K position. In line 9 we find Rachele's explicit request (what do I tell him?), i.e. a wh-question coming from her U position and directed to Sandro's K one: Rachele assigns her friend the complementary role of more knowledgeable. Sandro accepts this epistemic role and, from a $\mathrm{K}$ position, begins to formulate his advice in an assertive, unmitigated way (lines 11-13): The word love must be ELIMINATED from any form of dialogue. Rachele's replies are aligned. In line 14 , from an U position, she asks through a second wh-question why she should avoid the word "love", seeming amused by that. Sandro gives her his reasons, shifting from a K position (I'll tell you why right away) to a NKW/B position: unless you want him to run away, which corresponds to the apodosis of a conditional clause: if you do not want him to run away, whose protasis 
is in the above lines 11-13 (The word love must be ELIMINATED from any form of dialogue). In line 17 Rachele seems to accept his advice and makes a proposal, followed by Sandro's agreement (Good).

In this fragment both the specific social actions (Seeking advice-Giving advice) and the epistemic negotiation (Sandro replies from a K position to Rachele's request coming from an $\mathrm{U}$ and a NKW/B position) are aligned. Thus, the two epistemic positions are complementary and negotiated in a cooperative, friendly and affiliative way and the sequential structure of the interaction can be considered as closed: Rachele asks for advice, Sandro gives it, Rachele accepts it and Sandro ratifies it.

\subsection{The second excerpt}

This excerpt belongs to a corpus of crime case interactions and is taken from an episode of Quarto Grado, an Italian TV programme about crime cases, ${ }^{7}$ concerning the violent death of a little boy. The victim's mother, Veronica P., is suspected to be the killer. The interaction occurs between the TV moderator, Gianluigi Nuzzi (N) and one of his guests, the psychiatrist Massimo Picozzi (P).

1N: Allora il primo dato clamoroso che vi offriamo noi di Quarto Grado Well the first clamorous datum that we of Quarto Grado offer you

2 è questo, che lei non chattava con nessuno in nei minuti della is this, that she wasn't chatting with anyone during the minutes of

3 morte di Loris. Allora vuol dire Picozzi che ha fatto tutto da Loris' death. Picozzi so that means that she did everything on

4 sola?

her own?

5P: Ma sai tecnicamente uccidere in cosi poco tempo è But you know technically killing someone in such little time is

6 possibile perché francamente purtroppo infliggere la morte non è possible because honestly unfortunately inflicting death is not

7 cosi, complicato. É che psicologicamente non mi sta, ah so, complicated. I mean psychologically it does not convince me, ah

8 non non ci sta questa figura dal punto di vista del profilo. Ehm, this figure does not not fit from a profile point of view. Ehm,

9 noi abbiamo profili di mamme che uccidono. Ci sono donne con, we have profiles of mothers who kill. There are women with,

10 patologie mentali. Donne con, eh un passato di maltrattamenti verso mental illnesses. Women with, ehm a past of abuses towards

11 i figli. Con problemi di tossicodipendenza ne abbiamo parlato. their sons. With drug addiction problems we have talked about that.

12 Con, bisogno di vendetta rispetto al coniuge, con cui with, a need to take revenge against their partner, with whom

7 Its format includes the discussion of famous unsolved crimes among the moderator, commentators and experts. 
13 hanno dei conti in sospeso. Ma qui non ce n'erano. Quindi qui they have pending issues. But here there were none. Therefore here

un autocontrollo estremo e di organizzare tutto, in an extreme self-control and to organize everything, in an absolutely meticulous manner. It doesn't really convince me.

18N: Un sangue freddo che è improbabile che la donna la mamma possa aver A cold blood that it is unlikely that the woman the mum could have

Nuzzi, from the NKW/B position (i.e. by using a polar question) asks Picozzi, the expert, whether it is possible that Veronica could have killed her child alone (lines 3-4).

The psychiatrist's reply (lines 5-17) is completely aligned with the moderator's request, since he provides his opinion prevalently from the NKW/B position. He claims, indeed, that practically, technically it is possible that Veronica could have killed her child alone (lines 5-6), but he does not believe it (lines 7-13): he doubts that she could have done it, since Veronica's psychological profile does not fit well with that of murderous mothers and the supposed reaction of anger does not fit with Veronica's subsequent over-controlled behaviour. The psychiatrist goes on (second part of line 13, line 14 and first part of line 15) by opening, from a NKW/B position, a hypothetical scenario (we should consider a brief moment of anger...) that he rejects immediately after its formulation (line 17), by reaffirming his doubts (It doesn't really convince me).

The sequence is closed by the moderator (lines 18-19), who shows his agreement with the psychiatrist's words: Nuzzi indeed claims, from a NKW/B position - paraphrasing and summarizing what the expert has just said in his previous turn - that it is unlikely that Veronica could have maintained such "cold-blooded" behaviour for such a long time, if she were the killer.

Also in this excerpt, both the epistemic positions and social actions are aligned. The affiliative outcome is evident by the sequential structure: the moderator opens the sequence from the NKW/B by asking for an opinion; the specialist answers from the NKW/B position by displaying his own beliefs; the moderator closes the sequence by summarizing and ratifying what the psychiatrist has previously said.

\subsection{The third excerpt}

Differently from the previous ones, extract (3) is an example of misalignment and, as excerpt (1), it is taken from the same corpus of troubles-telling sequences. This is a typical example of asynchrony in a troubles-talk situation, as described by Jefferson and Lee (1981/1992): a troubles teller - in this case, Clara (C), a university student - bumps 
into an advice giver, instead of an expected troubles recipient. What is more, her friend Adriana (A) is an advice giver particularly critical and intrusive.

(3)

1C: Sto malissimo. Mi sento male.

I feel very bad. I feel sick.

2A: Glielo devi dire.

You have to tell him.

3C: No non glielo dico.

No I'm not going to.

4A: Glielo devi dire.

You have to tell him.

5C: Non glielo di' tu eh!

Don't You tell him!

6A: Ma che! Chi ci parla!

Certainly not! Nobody's going to tell him!

7 Cioè:, (.) Mado::',

I mean, (.) My God,

Clara has just told Adriana that the night before she innocently flirted with a young man that at a certain point kissed her. It was a kiss on the cheek - but only because she turned her face just in time! - however, now she feels bad, as if, in a sense, she had been unfaithful to her boyfriend. Clara, from the K position directed to the U one, simply describes her mood (line 1) as a consequence of the event previously narrated; she does not ask for advice, either explicitly or implicitly (there is no trace of request or solicitation). She doesn't say that she doesn't know how to get out of this situation, nor does she assign Adriana the epistemic role of more knowledgeable. Nonetheless, Adriana takes on this role.

She puts herself in a $\mathrm{K}$ position and, using the deontic expression you have to (lines 2, 4), she repeatedly gives Clara some very imperative advice (the linguistic formulas are the same of an order and only the context and the relationship - equal, symmetrical - allow us to consider them pieces of advice).

Clara's replies are clearly not aligned and the advice given is firmly resisted. She does not agree: even if she feels bad, she does not want to tell her boyfriend anything (line 3) and she does not want Adriana to do it either (line 5). Adriana (lines 6-7) strongly excludes this possibility.

From an epistemic viewpoint, Adriana and Clara assume two opposite and irreconcilable K positions. Negotiation and agreement appear quite impossible: each interactant remains anchored in her own position.

Unlike the previous two examples, the sequential structure seems to remain opened, in the sense that the participants are blocked at a communicative impasse. 


\subsection{The fourth excerpt}

This excerpt is taken from the same episode of Quarto Grado we presented in section 4.2. In this case, the moderator, Nuzzi, interviews another guest of his programme, Veronica P.'s defence lawyer, Villardita (V).

(4)

1N: Avvocato Villardita dunque per voi quella sagoma Attorney Villardita, so according to you that silhouette

2 non è Loris. is not Loris.

[...]

$6 \quad$ Non è Loris a rientrare?

It's not Loris who gets back in?

7V: Non per noi!

Not according to us!

8 Non è Loris a rientrare per il programma

Loris is not the one who gets back according to the programme

9 Amped Five che utilizza il filtro (Laplasciano) e utilizza il

Amped Five which makes use of the filter (Laplacian) and makes use

10 negativo e dosa la luminosità e pulisce

of the negative and measures the brightness and cleans up

11 l'immagine. Fino ad ora abbiamo guardato quell'immagine the image. Up to now we exclusively looked at the image

12 sempre ed esclusivamente ad occhio nudo. with the naked eye.

13 Ora l'immagine l'abbiamo guardata esclusivamente con un (.) Now we exclusively looked at the image with a (.)

14 importantissimo software che è utilizzato dalla very important software that is employed by the

15 polizia scientifica ed è utilizzato dall’FBI. scientific police and it is employed by the FBI.

16 E quel bambino non è Loris perché il bambino And that child is not Loris because the child

17 che esce ha una colorazione bianca e nera e il bambino che entra who goes out is in black and white and the child who gets in

18 >inequivocabilmente< è [assolutamente chiaro. is >unequivocally< [absolutely light-coloured.

19L:

[Magari si era tolto la maglia oppure [Maybe he took off his jumper or

20 aveva prima lo zainetto e poi non ce lo aveva più, eh initially he had his backpack and then he did not have it anymore, eh

Nuzzi, from a NKW/B position, i.e. by first using a declarative question (lines 1-2) and then a polar interrogative (line 6), asks the defence lawyer's opinion about the 
possibility that the child recorded by the cameras - coming back into the building where Veronica and her child lived and where, according to the prosecution, the child was killed by Veronica before leaving his body in a canal - could be another child and not the killed one. In other terms, as in excerpt (2), the moderator seems to solicit the attorney to reply from a NKW/B position.

Nonetheless, the attorney explicitly refuses to align with the moderator's request: he does not assume a NKW/B position, but a K one and explicitly says Not according to us! (line 7), which can be paraphrased as: it is not an opinion of ours, but it is the Amped Five software to show that it is not Loris. By rejecting to adopt the position solicited by the moderator, Villardita shows his disagreement by denying that the defence case is based on a subjective perspective and claims that the defensive college reached their conclusions ( $=$ the child recorded while coming back into the building is not Loris and therefore Veronica is not the killer) with the help of a sophisticated (and very important) program, "Amped Five" (lines 8-18). From an epistemic viewpoint, the declarative sentences (in the present and past indicative) and the adverbs of certainty (unequivocally and absolutely) are used by the attorney to communicate that he does not suppose, he does know for certain that the child recorded is not Loris.

The misalignment is clearly overt both from an epistemic viewpoint, since the attorney replies from a $\mathrm{K}$ position instead of the expected $\mathrm{B}$ position, and from a social action perspective, since the attorney refuses to reply by showing his own opinion (the expected reply); he answers indeed by appealing to the authority of the FBI which uses the same software employed by the defensive college.

The non-affiliative outcome is also evident from the sequential structure of the interaction in which the moderator's ratification is lacking. The excerpt goes on with the intervention of another guest, the journalist Grazia Longo (L), who from a NKW/B position overlaps the attorney and assumes the speakership by casting doubts (lines 19-20) on the defence's conclusion and advancing several possible alternatives to explain the change of colour shown in the video images: maybe (it's possible that) he took off his jumper (first hypothesis), or initially he had his backpack and then he did not have it anymore (second hypothesis).

\section{Conclusions}

In the present paper, we applied our model of epistemic stance to the analysis of four excerpts and we tried to show how the participants' management of the epistemic positions, not only of their social actions, can affect the sequential structure of the interaction.

Specifically, excerpts (1) and (2) are overt examples of epistemic and social action alignment. The interlocutors assume roles consistent with the speakers' expectations: in the first one, the interlocutor replies from a $\mathrm{K}$ position by giving the requested advice; in the second one, the psychiatrist replies from a NKW/B position by expressing his requested opinion. In both cases, the dialogical sequence seems to be closed: in the first excerpt, there are four aligned adjacency pairs made up of questions 
and answers: the request for advice is followed by the advice giving, the acceptance of the advice and its ratification. In the second excerpt, there is a triplet made up of a request for opinion, an aligned reply and a ratification.

On the contrary, excerpts (3) and (4) are examples of epistemic and social action misalignment. The interlocutors refuse (implicitly or explicitly) to assume roles consistent with the speakers' expectations. In the third excerpt, the interlocutor gives some unrequested advice and the dialogical structure seems to come to an impasse. In the fourth excerpt, the lawyer refuses to express his opinion and the dialogical sequence seems to remain opened. In both cases, the misalignment seems to lead to slightly conflictual outcomes, displaying relational disagreement.

These results do not allow generalization, but further quantitative analysis could be undertaken to investigate these supposed relations.

\section{Transcription notes}

[]

[[ Underlining CAPITALS

${ }^{\circ}$ Degree signs ${ }^{\circ}$

(.) $(.).(.$.

(4")

((comment))

(single parentheses)

Co::lons

Comma,

Question mark?

Exclamation mark!

Full stop.

' (Apostrophe)

Hyphen-

$>$ he said<

$=$

hhh

.hh

te(h)xt
Square brackets mark the start and end of overlapping speech.

Double brackets indicate simultaneous speech orientations to prior turn. Indicates emphasis.

Mark speech that is hearably louder than surrounding speech.

Enclose hearably quieter speech.

Indicates a micropause.

Indicates a timed pause.

Additional comments from the transcriber, e.g. about features of context or delivery.

Transcriptionist doubt.

Show degrees of elongation of the prior sound.

Continuation marker; indicates a suspensive tone, irrespective of grammar.

Questioning intonation.

Exclamatory intonation.

Falling, stopping intonation, irrespective of grammar.

Sounds' omission or contraction.

Marks a cut-off of the preceding sound.

'Greater than' and 'lesser than' signs enclose speeded-up talk. They are used the other way round for slower talk.

'Equals' signs mark the immediate 'latching' of successive talk, whether of one or more speakers, with no interval.

Laughter.

Audible inbreaths.

Speech with simultaneous laughter.

\section{References}

Atkinson J.M., Heritage J. (eds.). 1984. Structures of social action. Cambridge.

Biber D. 2004. Historical patterns for the grammatical marking of stance: A cross-register comparison. - Journal of Historical Pragmatics 5: 107-135. 
Biber D., Finegan E. 1989. Styles of stance in English: Lexical and grammatical marking of evidentiality and affect. - Text 9.1: 93-124.

Bongelli R., Riccioni I., Zuczkowski A. 2013. Certain-uncertain, true-false, good-evil in Italian political speeches. - Poggi I., D’Errico F., Vincze L., Vinciarelli A. (eds.). Multimodal communication in political speech. Shaping minds and social action. Berlin: 164-180.

Bongelli R., Zuczkowski A. 2008. Indicatori linguistici percettivi e cognitivi. Roma.

Englebretson R. 2007. Stancetaking in discourse. Amsterdam, Philadelphia.

Heritage J. 2010. Questioning in Medicine. - Freed A., Ehrlich S. (eds.). "Why Do You Ask?”: The function of questions in institutional discourse. New York: 42-68.

Heritage J. 2012a. Epistemics in action: Action formation and territories of knowledge. Research on Language and Social Interaction 45.1: 1-29.

Heritage J. 2012b. The epistemic engine: Sequence organization and territories of knowledge. - Research on Language and Social Interaction 45.1: 30-52.

Heritage J. 2013. Action formation and its epistemic (and other) backgrounds. - Discourse Studies 15.5: 551-578.

Hintikka J. 1962. Knowledge and belief. An introduction to the logic of the two notions. Ithaca. Jaffe A. 2009. Stance: Sociolinguistic perspectives. Oxford.

Jefferson, Lee 1981/1992 = Jefferson G., Lee J.R.E. 1981. The rejection of advice: Managing the problematic convergence of a 'troubles-telling' and a 'service encounter'. - Journal of Pragmatics 5.5: 399-422. [also in Drew P., Heritage J. (eds.). 1992. Talk at work: Interaction in institutional settings. Cambridge: 521-548].

Kamio A. 1994. The theory of territory of information. The case of Japanese. - Journal of Pragmatics 21.1: 67-100.

Kamio A. 1997. Territory of information. Amsterdam, Philadelphia.

Ochs E. 1996. Linguistic resources for socializing humanity. - Gumperz J., Levinson S. (eds.). Rethinking linguistic relativity. Cambridge: 407-437.

Quirk R., Greenbaum S., Leech G., Svartvik J. 1985. A comprehensive grammar of the English language. London.

Riccioni I., Bongelli R., Zuczkowski A. 2013. The communication of certainty and uncertainty in Italian political media discourses. - Fetzer A. (ed.). The pragmatics of political discourse. Amsterdam, Philadelphia: 125-165.

Riccioni I., Bongelli R., Zuczkowski A. 2014. Mitigation and epistemic positions in troubles talk: The giving advice activity in close interpersonal relationships. Some examples from Italian. - Language \& Communication 39: 51-72.

Zuczkowski A., Bongelli R., Riccioni I. 2011. Proposizione costitutiva di mondo e indicatori linguistici percettivi e cognitivi. - Hölker K., Marello C. (eds.). Dimensionen der Analyse von Texten und Diskursen. Festschrift für János Sándor Petöfi zum achtzigsten Geburstag. Dimensioni dell'analisi di testi e discorsi. Festschrift für János Sándor Petöfi in occasione del suo ottantesimo compleanno. Berlin: 41-61.

Zuczkowski A., Bongelli R., Riccioni I. 2017. Epistemic stance in dialogue. Knowing, Unknowing, Believing. Amsterdam, Philadelphia.

Zuczkowski A., Bongelli R., Vincze L., Riccioni I. 2014. Epistemic stance: Knowing, Unknowing, Believing (KUB) positions. - Zuczkowski A., Bongelli R., Riccioni I., Canestrari C. (eds.). Communicating certainty and uncertainty in medical, supportive and scientific contexts. Amsterdam, Philadelphia: 115-138. 